TI 2014-017/VII

Tinbergen Institute Discussion Paper

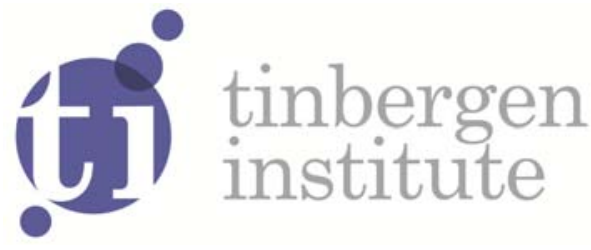

\title{
Don't demotivate, discriminate
}

\author{
Jurjen J.A. Kamphorst \\ Otto H. Swank
}

Erasmus School of Economics, Erasmus University Rotterdam, and Tinbergen Institute. 
Tinbergen Institute is the graduate school and research institute in economics of Erasmus University Rotterdam, the University of Amsterdam and VU University Amsterdam.

More TI discussion papers can be downloaded at http://www.tinbergen.nl

Tinbergen Institute has two locations:

Tinbergen Institute Amsterdam

Gustav Mahlerplein 117

1082 MS Amsterdam

The Netherlands

Tel.: +31(0)205251600

Tinbergen Institute Rotterdam

Burg. Oudlaan 50

3062 PA Rotterdam

The Netherlands

Tel.: +31(0)10 4088900

Fax: $+31(0) 104089031$

Duisenberg school of finance is a collaboration of the Dutch financial sector and universities, with the ambition to support innovative research and offer top quality academic education in core areas of finance.

DSF research papers can be downloaded at: http://www.dsf.nl/

Duisenberg school of finance

Gustav Mahlerplein 117

1082 MS Amsterdam

The Netherlands

Tel.: +31(0)20 5258579 


\section{Don't Demotivate, Discriminate*}

\author{
Jurjen J.A. Kamphorst \\ Erasmus School of Economics \\ and Tinbergen Institute \\ kamphorst@ese.eur.nl
}

Otto H. Swank

Erasmus School of Economics

and Tinbergen Institute

swank@ese.eur.nl

December 20, 2013

Abstract: This paper offers a new theory of discrimination in the workplace. We consider a manager who has to assign two tasks to two employees. The manager has superior information about the employees' abilities. We show that besides an equilibrium where the manager does not discriminate, equilibria exist where the manager discriminates in favor of the employee whom the employees expect to be favored. The manager, who has no taste for discrimination, discriminates in order to avoid demotivating the 'favorite'. We show that the non-discriminatory equilibrium is unstable. Yet the manager would prefer to commit not to discriminate.

JEL codes: D82, J71, M51, M54,

Keywords: discrimination, confidence management, Bayesian games

${ }^{*}$ We are grateful to Robert Dur for many insightful discussions and comments. We are also grateful for many other helpful discussions. In particular we thank Martin Bøg, Raicho Bojilov, Christophe Bravard, Richard Chisik, Suzanne Bijkerk, Julian Emami-Namini, Christian Ewerhart, Robert Gibbons, Freek van Gils, Vladimir Karamychev, Phillipe Marcoul, Ewa Mendys, John Morgan, Jörg Oechssler, Stephanie Rosenkranz, Dana Sisak, Kathryn Shaw, Joel Sobel, Eric van den Steen, Lars van Vianen, Marie Claire Villeval, Bauke Visser, Bastian Westbrock, and participants of the ESE brown bag seminar. 


\section{Introduction}

Suppose you, John, and his father, Pete, run a small business where social skills matter a lot. John's father is formally responsible for this business. You and John are juniors. Both of you are uncertain about your own skills and each other's skills. Pete, by contrast, is very experienced. You and John are sure that he has a good view of your and John's skills. On a certain day, John's father announces that he resigns and that he confers the responsibility for the business to his son. He told you and his son that this "promotion" decision was based on his perception that his son has the better social skills.

How is your perception of your social skills affected by Pete's promotion decision? You may conclude that John has better social skills than you have. Pete made him responsible for the business after all. In a similar way, Pete's promotion decision may boost John's perception of his social skills. Alternatively, and perhaps more likely, you and John may believe that because John is Pete's son, Pete's promotion decision contains little information about your and John's skills. Only if John's skills were very poor, Pete would have chosen you. Conveying responsibility to you, however, would have damaged John's perception of his social skills severely.

In the above example inferences depend on beliefs. The effect of Pete's promotion decision on your perception of your social skills depends on your belief about whether or not Pete treats his son as the favorite. As important is that John's and your beliefs may affect Pete's promotion decision. If conveying responsibility to you severely damages John's perception of his social skills, it may be in the interest

of the business to convey responsibility to John even though your social skills are better developed.

This paper offers a new theory of discrimination in the workplace. We model a situation where two tasks have to be performed, a major task and a minor one. A manager must assign these two tasks to two employees. One might associate the major task with a promotion. The model we propose has three important features. First, an employee's effort and his ability are complements. Second, the manager has better information about the employees' abilities than the employees themselves. Finally, the manager can only convey information about the employees' abilities through the task-assignment decision. We say that the manager follows a 
discriminatory strategy if she intentionally sometimes gives the major task to the employee with the lower ability.

We start with analyzing a simple model in which employees' abilities are uniformly distributed, and tasks contribute equally to the output of the organization. We show that in this environment the manager follows an assignment rule that favors one of the employees. The reason is that the manager has an incentive to confirm any belief that implies that one employee is favored by the other. The above example gives the intuition. If both you and John believe that John will be promoted unless his social skills are by far inferior to yours, promoting you would imply that John's skills are very poor. This would destroy John's motivation. As a result, it is not only in John's interest that he is promoted. It is also good for the business. In the basic model, an equilibrium also exists in which the manager does not discriminate. We show that this equilibrium is optimal from the manager's perspective. However, we also show that this equilibrium is not stable in the sense that the slightest anticipation of discrimination would push behavior to a discriminatory equilibrium. The implication is that 'new' reasons to expect discrimination become self-fulfilling relatively easily. Our model thus explains why discrimination has been prevalent in many different forms throughout history and cultures.

Having established that in the most neutral version of our model discrimination is almost unavoidable, we proceed by analyzing less neutral versions of our model. First, we relax the assumption that tasks are equally productive. We show that the more tasks differ in importance, the less managers discriminate. The intuition is straightforward. Managers tend to confirm beliefs in order to avoid demotivating the favorite. The cost is a distorted allocation of tasks. Discrimination jeopardizes good matches between people and tasks. The more tasks differ in importance, the more important it is that the more able person performs the more productive task.

Second, we replace the assumption that employees are equally able ex ante with the assumption that the ability of each employee is drawn from a different distribution function. Specifically, we assume that both employees believe that top talents come from one identifiable group of workers. These beliefs might be sheer prejudices. We show that such prejudices lead to stronger incentives to discriminate. In the interest of the firm, a manager tends to confirm prejudices.

In our model the tendency to discriminate stems from fear to demotivate the 
favorite. The extent to which the favorite is demotivated depends on his initial beliefs. One might think that if the favorite already believes that he is not very able, passing him is less costly. We show that this intuition is correct. Managers' incentives to discriminate are stronger in environments where employees are more likely to be able.

Our model is not only applicable to gender, race, religion or family ties as grounds for discrimination. It can be applied to all possible differences between employees that may lead to different beliefs. For example, once the employees believe that the manager favors one employee because this employee and the manager both like red wine, the manager has an incentive to confirm those beliefs. This makes our message very negative: we expect discrimination or favoritism to be recurring and ubiquitous on the workfloor. The wide variety of possible grounds for discrimination makes it for the government hard to combat it by enacting laws that prohibit discrimination. Of course, the government can prohibit discrimination against women. However, it seems more difficult to prohibit discrimination against white wine lovers. More optimistically, our results suggest that organisations themselves may avoid discrimination by a proper design of tasks or jobs. In addition, our paper shows that in tournament settings discrimination is more likely to occur than in up-or-out settings.

In our model the manager has no taste for discrimination (Becker, 1957). Moreover, the manager observes the employees' abilities, implying that she does not need to use a physical attribute as a signal of employee productivity (Phelps, 1972). Tastes for discrimination or fear for being evaluated on the basis of a physical attribute may give rise to beliefs that eventually lead to discrimination. In our model, however, we do not need that employees belong to a well-defined group, as the above example of sharing a love for red wine suggests. For this reason, our model can also be regarded as a model of favoritism.

\section{Literature}

The model we develop builds on the recent literature on confidence management. Key in this literature is that employees have imperfect knowledge about their abilities, and that managerial decisions contain information about their abilities (Bénabou and Tirole, 2003). The implication is that managerial decisions may affect 
employees' motivation. Ishida (2006) applies this idea to promotion decisions. In his model, effort and ability are complements, and the manager wants more able employees to be promoted. Ishida shows that in this setting managers are inclined to promote employees at lower ability levels to boost their self-confidence. Crutzen et al. (2013) examine a tournament model à la Lazear and Rosen (1981) in which two employees compete for a promotion or an important task. Like us, the manager's task assignment decision affects the employees' perceptions of their abilities. Unlike us, the manager also has the option to abstain from differentiating employees. Their main result is that in order to avoid damaging the self-confidence of one of the employees, managers tend to avoid promotion or allocation of tasks on the basis of abilities. The intuition for this result is well captured by a quote from Takeuchi (1985), “ .. the promotion of only one or two persons will cause the remaining twentyodd employees to lose their will to work". Crutzen et al. (2013) provide an explanation for why promotions are sometimes seniority based rather than merit based. Likewise, Prendergast (1992) argues that Japanese firms wait long before they differentiate between low potential and high potential employees so as not to demotivate low potential employees. The studies mentioned above share with our paper that decisions of managers contain information that influences the motivation of subordinates. Neither of these papers, however, show that confidence management can induce managers to discriminate. Crutzen et al. (2013) restrict attention to symmetric equilibria, thereby excluding discrimination. In Prendergast (1992), employees are not competing for tasks or a promotion.

Our paper also contributes to the huge literature on discrimination. In our explanation for discrimination, beliefs play an essential role. In this sense, our paper is most closely related to the literature using self-fulfilling prophecy models (SFPMs) [see e.g. Arrow (1973), Coate and Loury (1993) and Mailath et al. (2000)]. In these papers, an employee must make an investment to be qualified for a skilled job or a demanding task. Managers do not observe employees' investment decisions. As a result, whether or not a manager gives an employee a demanding task depends on her belief about the likelihood that an employee has invested. In SFPMs a distinction is usually made between bad and good equilibria. In bad equilibria, managers correctly believe that employees did not invest. In good equilibria, managers correctly believe that employees did invest. Discrimination is said to occur if a bad equilibrium exists 
for one group and a good equilibrium exists for another group. In addition to the emphasis on beliefs, our model is similar to SFPMs in that ex post the manager's decision is optimal for the firm. However, an important difference between our model and SFPMs is the nature of discrimination. In SFPMs, discrimination is a possible symptom. The occurrence of a bad equilibrium is the core problem. For example, a situation where both males and females are trapped in a bad equilibrium (no discrimination) might be regarded as inferior to a situation where females are in a bad equilibrium and males are in the good equilibrium. To put this differently, in SFPMs one group is not discriminated against the other group. In our model, the focus is on how one employee is treated relative to another employee. Another important difference between SFPMs and our model is that SFPMs revolve around managers who are uncertain about which employee is the better candidate, and she selects the one she expects to be better. In our model, the manager knows which employee is better. Yet she may still select the weaker employee.

As discussed above, in our model the manager's promotion decision maximizes the firm's profits ex post. Our explanation for discrimination is therefore not based on some discriminatory preference of the manager or of some worker [see e.g. Becker (1957) and Arrow (1973) for early examples of taste-based discrimination models] or on the enforcement of some social norm as in Akerlof (1985). In fact, we show that the manager would typically want to commit to the non-discriminatory promotion rule. Of course the presence of discriminatory preferences in a society can cause the anticipation of discrimination. Such anticipation is enough to generate discrimination by managers who would be fair otherwise.

Pęski and Szentes (2013) have developed a model in which agents are repeatedly matched and must decide with whom to cooperate. Their model predicts (partial) segregation. An agent may choose not to enter into a profitable relationship with an agent of another group now, because such a relationship would reduce the profitability of relationships with agents of his own group later. Our paper shares with Pęski and Szentes that discrimination arises spontaneously. Moreover, like Pęski and Szentes, our model can explain the finding from experiments that even when groups are artificially formed, biases to individuals of their own group arise easily. In our model this would require that artificially formed groups affect beliefs. Our paper deviates from Pęski and Szentes in two main respects. First, our model deals 
with discrimination on the workfloor, while the Pęski and Szentes model focuses on discrimination of people who have to decide with whom to interact. The Pęski and Szentes model is therefore better suited for explaining segregation. Our model is better suited for understanding the existence of glass ceilings. Second, beliefs are key in our explanation of discrimination. A manager discriminates out of fear for demotivating the favorite. In Pęski and Szentes, stigmatization is key in explaining discrimination. Individuals do not interact with individuals from the other group out of fear for being stigmatized by members of their own group.

We are aware that many more explanations for discrimination exist. For example, in Milgrom and Oster (1987) potential new employers do not observe the skills of disadvantaged employees. Promotion of disadvantaged employees would reveal their talents to competitors. This provides an incentive to managers not to promote disadvantaged employees. Lazear and Rosen's (1990) explanation for why females are less likely be promoted than males rests on the assumption that women are more able than men in nonmarket activities. This increases the probability that women quit the firm, thereby weakening manager's incentives to promote women. This paper is not intended to replace all existing theories of discrimination. Rather we show that on the workfloor, discrimination is very likely, that it can take many forms, and that it is hard to combat.

\section{The task assignment game}

We consider a unit, which consists of a manager, $M$, and two employees, 1 and 2 . In the unit two tasks have to be performed, a minor task and a major one. ${ }^{1}$ It is the manager's job to assign the tasks in such a way that the unit's output is maximized. We model this as follows. If employee $i, i \in\{1,2\}$, receives the major task, he chooses effort $e_{i}\left(e_{i}>0\right)$ to produce output $y_{i}=\eta a_{i} e_{i}$, where $a_{i}$ denotes $i$ 's ability, and $\eta \geq 1$ is a measure of the importance of the major task relative to the minor task. If employee $i$ receives the minor task, he chooses effort to produce output $y_{i}=a_{i} e_{i}$. An important feature of our model is that the manager has superior information about $a_{i}$. Specifically, the manager observes $a_{1}$ and $a_{2}$, while the employees only

\footnotetext{
${ }^{1}$ Our game can also be formulated as a promotion game. In a promotion setting, the major task would mean getting promoted.
} 
know that $a_{1}$ and $a_{2}$ are independently drawn from a uniform distribution on the interval $[0,1] .^{2}$ At the beginning of the game, the manager assigns tasks, $m \in\{1,2\}$, where $m=i$ denotes that she gives the major task to employee $i$.

The employees want to contribute to the unit, but are effort averse. More specifically, employee $i$ 's preferences are represented by

$$
U_{i}\left(e_{i}\right)=\left\{\begin{array}{cc}
\eta E\left(a_{i} \mid m\right) e_{i}-\frac{1}{2} e_{i}^{2} & \text { if } m=i \\
E\left(a_{i} \mid m\right) e_{i}-\frac{1}{2} e_{i}^{2} & \text { if } m \neq i
\end{array}\right.
$$

where $E\left(a_{i} \mid m\right)$ is $i$ 's expectation of his ability, conditional on the task assignment decision $m$. The manager aims at maximizing output

$$
U_{M}\left(m, a_{1}, a_{2}\right)=\sum_{i=1}^{2} y_{i}
$$

The timing of the model is as follows. At the beginning of the game nature draws $a_{1}$ and $a_{2}$. The manager observes $a_{1}$ and $a_{2}$, but the employees do not. Next, the manager assigns tasks. The employees update their beliefs about their abilities, and choose an effort level. Finally, payoffs are realized.

In our game, the employees' effort strategies are simple. Each employee chooses an effort level that is equal to the importance of the task times his expected ability, conditional on the assignment decision ${ }^{3}$

$$
e_{i}=\left\{\begin{array}{cc}
\eta E\left(a_{i} \mid m\right) & \text { if } m=i \\
E\left(a_{i} \mid m\right) & \text { if } m \neq i
\end{array}\right.
$$

Equation (3) shows that an employee's effort is a positive function of his perception of his ability. Of course the reason is that in our game effort and ability are complements. A key feature of our model is the effect of the manager's task assignment decision on the employees' perceptions of their abilities. In the words of Bénabou and Tirole (2003, p. 493), this feature of the model allows for confidence

\footnotetext{
${ }^{2}$ The information structure is common in studies where organizational decisions, like the assignment of tasks, influence employees' motivation (see, for instance, Prendergast, 1992, Bénabou and Tirole, 2003, and Ishida, 2006).

${ }^{3}$ How the allocation decision affects the expected value of $a_{i}$ depends on the manager's allocation strategy. This allows for confidence management. To keep notation simple, we suppress the latter and simply write the expectation as $E\left(a_{i} \mid m\right)$.
} 
management. Our set-up is the easiest set-up we could think of to show how confidence management leads to discrimination. Confidence management requires that an employee's effort depends on his perception of his ability [see (3)].

The assignment strategy of the manager, $s^{M}\left(a_{1}, a_{2}\right)$, stipulates her task assignment decision, $m$, for all combinations of $a_{1}$ and $a_{2}$. We identify perfect BayesianNash equilibria in which (i) employees' effort strategies are optimal, given their beliefs about their abilities; (ii) the manager's assignment strategy is optimal, given employees' effort strategies and beliefs; and (iii) beliefs are updated according to Bayes' rule. We identify equilibrium assignment strategies in which the task assignment decisions do depend on $a_{1}$ and $a_{2}$.

To drive home our results in a simple way, we start with analyzing the case that both tasks are equally important $\eta=1$. We refer to this game as the basic game.

\section{Analysis of the basic game}

In this section we first show that our basic model has three equilibria, two of which are discriminatory. Next, we show that only the discriminatory equilibria are stable. Finally, we show that it would be optimal for the manager if she could commit to no discrimination. We emphasize that this tension between stability and efficiency is not the result of externalities. Rather, workfloor anticipations force the manager into behavior she would rather avoid.

\subsection{Equilibria}

Recall from Section 3 that for $\eta=1$ the optimal effort strategy of the employee is given by $e_{i}=E\left(a_{i} \mid m\right)$. Now consider the manager. She prefers $m=1$ to $m=2$ if $m=1$ yields a higher total output than $m=2$. As $m$ affects the behavior of the employees through their beliefs, this amounts to

$$
a_{1} E\left(a_{1} \mid m=1\right)+a_{2} E\left(a_{2} \mid m=1\right) \geq a_{1} E\left(a_{1} \mid m=2\right)+a_{2} E\left(a_{2} \mid m=2\right)
$$

The manager is indifferent between sending $m=1$ and sending $m=2$ if

$$
a_{1}=t a_{2}, \text { where } t=\frac{E\left(a_{2} \mid 2\right)-E\left(a_{2} \mid 1\right)}{E\left(a_{1} \mid 1\right)-E\left(a_{1} \mid 2\right)}
$$




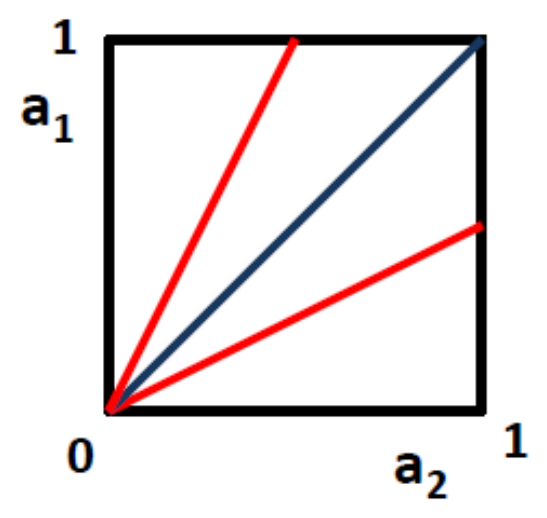

Figure 1: Each of the diagonal lines corresponds to one equilibrium. Any point above (below) such a line would imply that Employee 1 (2) would get the major task.

Equation (4) shows that the manager's task-assignment strategy is characterized by a straight line through the origin. This straight line determines for any combination $\left(a_{1}, a_{2}\right)$ which employee gets the major task. If $a_{1} \geq t a_{2}$, the manager gives the major task to employee 1 , while if $a_{1}<t a_{2}$, she gives it to employee 2 . The next step is to determine this line more precisely.

In equilibrium, the employees' beliefs about their abilities conditional on the task assignment decision have to be consistent with the manager's assignment strategy. Using that beliefs should be self-confirming, we obtain Proposition 1.

Proposition 1 Three equilibria of the basic game exist in which the manager's assignment strategy depends on $a_{1}$ and $a_{2}$. These strategies are characterized by $t^{*}=1$, $t^{*}=\frac{1}{2}$ and $t^{*}=2$.

Proof: Suppose $t \leq 1$. We first calculate the beliefs for both employees, given the assignment strategy implied by (4). Using these beliefs, we solve (4) for $t$. The beliefs are: $E\left(a_{1} \mid 1\right)=\frac{\int_{0}^{1} \int_{t_{2}}^{1} a_{1} d a_{1} d a_{2}}{\int_{0}^{1} \int_{t a_{2}}^{1} d a_{1} d a_{2}}=\frac{3-t^{2}}{6-3 t}, E\left(a_{2} \mid 1\right)=\frac{\int_{0}^{1} \int_{t a_{2}}^{1} a_{2} d a_{1} d a_{2}}{\int_{0}^{1} \int_{t a_{2}}^{1} d a_{1} d a_{2}}=\frac{3-2 t}{6-3 t}$, $E\left(a_{2} \mid 2\right)=\frac{\int_{0}^{1} \int_{0}^{t a_{2}} a_{2} d a_{1} d a_{2}}{\int_{0}^{1} \int_{0}^{t a_{2}} d a_{1} d a_{2}}=\frac{2}{3}$, and $E\left(a_{1} \mid 2\right)=\frac{\int_{0}^{1} \int_{0}^{t a_{2}} a_{1} d a_{1} d a_{2}}{\int_{0}^{1} \int_{0}^{t t a} d a_{1} d a_{2}}=\frac{1}{3} t$. The equilibrium values of $t$ result from solving

$$
t=\frac{\frac{2}{3}-\frac{3-2 t}{6-3 t}}{\frac{3-t^{2}}{6-3 t}-\frac{1}{3} t}
$$

yielding the solutions $t^{*}=1$ and $t^{*}=\frac{1}{2}$. The case that $t>1$ mirrors the case that $t \leq 1$. It yields a solution $t^{*}=2$. 
Proposition 1 describes three equilibria. Figure 1 depicts them. In the equilibrium where $t^{*}=1$ the manager always assigns the major task to the more able employee. This equilibrium is quite intuitive. The other two equilibria are, at first glance, less intuitive. In the equilibrium where $t^{*}=\frac{1}{2}$ the probability employee 1 is given the major task is three times higher than the probability employee 2 is given the major task, even though ex ante the employees are identical. Why is the task assignment strategy $t^{*}=\frac{1}{2}$ self-confirming?

Suppose that employee 1 is a male and employee 2 is a female. In a world where the employees expect that males get the major tasks unless females are at least twice as able as males, i.e. $t=\frac{1}{2}$, giving the minor task to the female has a strong adverse effect on the male's perception about his ability. It implies that the ability of the male must be smaller than $\frac{1}{2}(=t$; see Figure 2). Consequently, the task assignment decision has a large impact on the motivation of the man. In contrast, the female is not nearly affected as much by the task assignment decision. She knows that even if she has maximal ability, $a_{2}=1$, she would get the minor task only half of the time. As a result, her self-confidence remains relatively intact even if she gets the minor task. All in all, the manager is reluctant to give the major task to a female: the male employee needs it more to keep morale high. More generally, the anticipation of discrimination becomes self-fulfilling as the task assignment decision matters more for the confidence of the employee who expects to be favored relative to the employee who expects to be disfavored.

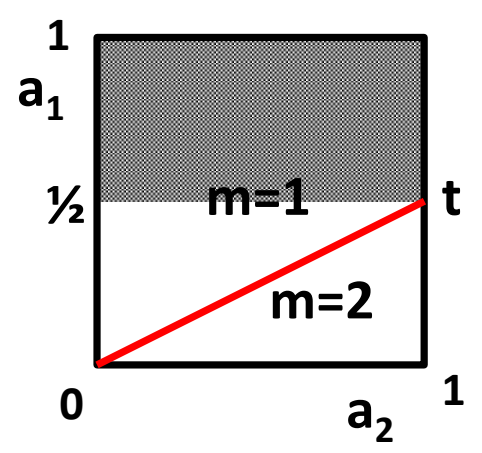

Figure 2: The shaded area indicates the ability vectors which receive zero probability conditional upon Employee 2 getting the major task. 


\subsection{Stability}

Having established that our basic game has three equilibria, the question arises which of the three equilibria are most likely. To answer this question, we investigate the stability of the equilibria. Specifically, suppose that the beliefs about the task assignment probabilities held by both employees, say $\hat{t}$, differ from the equilibrium beliefs. Without loss of generality suppose that $\hat{t}<1$. We say that the equilibrium $t^{*}=1$ is stable if for $\hat{t}$ close to 1 , the manager's optimal response to $\hat{t}$ is even closer to 1 , i.e. $t>\hat{t}$. Proposition 2 shows that the $t^{*}=1$ equilibrium is unstable, while the $t^{*}=\frac{1}{2}$ and $t^{*}=2$ equilibria are stable.

Proposition 2 The $t^{*}=\frac{1}{2}$ and $t^{*}=2$ equilibria of the basic game are stable, but the $t^{*}=1$ equilibrium is unstable.

Proof: Consider some arbitrary belief $\hat{t}$, where w.l.o.g. $\hat{t} \in[0,1]$. By Bayesian updating we obtain (see the proof of Proposition 1): $E\left(a_{1} \mid 1\right)=\frac{3-\hat{t}^{2}}{6-3 \hat{t}}, E\left(a_{2} \mid 1\right)=\frac{3-2 \hat{t}}{6-3 \hat{t}}$, $E\left(a_{2} \mid 2\right)=\frac{2}{3}$, and $E\left(a_{1} \mid 2\right)=\frac{1}{3} \hat{t}$. The best response by the manager equals

$$
t=\frac{\frac{2}{3}-\frac{3-2 \hat{t}}{6-3 \hat{t}}}{\frac{3-\hat{t}^{2}}{6-3 \hat{t}}-\frac{1}{3} \hat{t}}=\frac{1}{3-2 \hat{t}}
$$

We now check when $t>\hat{t}$.

$$
\begin{aligned}
\frac{1}{3-2 \hat{t}} & >\hat{t} \\
2 \hat{t}^{2}-3 \hat{t}+1 & >0 \\
(2 t-1)(t-1) & >0
\end{aligned}
$$

This only holds on $\hat{t} \in[0,1]$ if $t<\frac{1}{2}$. In contrast, for $\hat{t} \in\left(\frac{1}{2}, 1\right)$ we obtain $t<\hat{t}$. The implication is that if $\hat{t} \in\left(\frac{1}{2}, 1\right)$, the manager has an incentive to follow a task assignment rule that favors employee 1 even more than anticipated. Similarly $t>\hat{t}$ for $\hat{t} \in(1,2)$ and $t<\hat{t}$ for $\hat{t}>2$. Thus $t=\frac{1}{2}$ and $t=2$ are stable equilibria, while $t=1$ is unstable. The proposition follows.

Proposition 2 is the result of two effects. The first effect has already been explained below Proposition 1. If the employees expect some degree of discrimination in favor of males, $\hat{t}<1$, then giving the major task to a female has a larger effect 
on the morale of males than on the morale of females. This gives an incentive to the manager to give major tasks to males. The second effect is that a good morale is more important for more able employees. In the extreme case that $a_{1}=0$, the manager does not benefit from boosting employee 1's morale. This explains why there is a limit to the extent to which a manager is willing to confirm beliefs. If $\hat{t}<\frac{1}{2}$, the manager's optimal response is characterized by $t>\hat{t}$.

Note that our model does not predict whether there is discrimination against Employee 1 or there is discrimination against Employee 2. In the example of the introduction, it is well possible that the father discriminates against his son, because the father is known for being averse to favoritism.

Proposition 2 describes an alarming result. It shows that in a very neutral setting, the equilibria with discrimination are stable, while the equilibrium without discrimination is not stable. This helps to understand why discrimination is widespread, from all times, and hard to conquer.

\subsection{Efficiency}

Proposition 2 suggests that the discriminatory equilibria are the more plausible ones in our basic game. Now we show that discrimination is costly to the manager. She would want to commit to the non-discriminatory rule, if possible. Moreover, even though each employee would enjoy being favored by the assignment rule to some extent, the ex ante expected payoff to each employee is maximized without discrimination.

Proposition 3 Consider the basic game. Suppose the manager can commit to assignment rule $t$. Then

- The manager would prefer to commit to $t=1$.

- Each employee would prefer some discrimination in his favor, i.e. $t<1$ for $i=1$ and $t>1$ for $i=2$.

- The ex ante expected payoff to each employee is maximized if the manager commits to $t=1$.

Proof: See Appendix A 
The intuition of Proposition 3 is straightforward. The basic model is completely symmetric in the sense that tasks are equally important. As a result, the task assignment decision is a device for conveying information about the employees' abilities. If $t=1$, the task assignment decision contains most information about the employees' abilities.

Proposition 3 also implies that a random task assignment, or alternatively, a task allocation on the basis of seniority is not optimal. Such task assignment rules would completely break the relationship between task assignment and the employees' abilities. As a result, the task assignment decision would not contain any information about the employees' abilities. This would amount to $t=0$ or $t \rightarrow \infty$. Proposition 3 shows that these values are not optimal.

\section{Analysis of the task assignment game}

The basic game is a clear simplification. Typically the tasks will differ in their importance to the firm. ${ }^{4}$ In this section we return to the task assignment game where $\eta \geq 1$. We show three results. First, a difference in task importance reduces the degree of discrimination. Second, unless the difference in tasks is large, discrimination is still an equilibrium outcome. Third, as long as discriminatory equilibria exist, the non-discriminatory equilibrium remains unstable. In short, the analysis of the basic game extends to the full task assignment game unless the difference in relative task importance becomes too large. This is formally stated in the next proposition. The proof is relegated to Appendix B.

Proposition 4 Consider the task assignment game, with $\eta>1$. W.l.o.g. let $t \leq 1$. As $\eta$ increases, any discriminatory assignment rule involves weaker discrimination. If $\eta \geq \sqrt{1.5}$, the unique equilibrium assignment rule is non-discriminatory. Moreover, the discriminatory equilibrium is stable if it exists, i.e. for $\eta<\sqrt{1.5}$. The non-discriminatory equilibrium is stable only if it is unique, i.e. if $\eta \geq \sqrt{1.5}$.

Figure 5 illustrates how the discriminatory equilibrium depends on $\eta$. Clearly, the more the two tasks differ in importance, the less the manager disciminates. The

\footnotetext{
${ }^{4}$ See also Lazear and Rosen (1990) and Ishida (2012), where tasks are assigned based on promotions.
} 
intuition is straightforward. Suppose $t<1$. Recall that if $a_{2}>a_{1}$, Employee 2 is the better candidate for the major task in terms of both productivity and motivation: $E\left(a_{2} \mid 2\right)>E\left(a_{1} \mid 1\right)$. Giving the task to Employee 1 when $a_{1} \leq a_{2}$ therefore implies lower performance at the important task. The reason why the manager may still promote Employee 1 is that Employee 1 would be disproportionately demotivated if he is passed: $E\left(a_{1} \mid 2\right)<E\left(a_{2} \mid 1\right)$. Thus the performance at the less important task suffers relatively much if it is given to Employee 1. As $\eta$ increases, the motivation of the worker at the minor task becomes relatively less important. Therefore the manager will discriminate less, if at all.

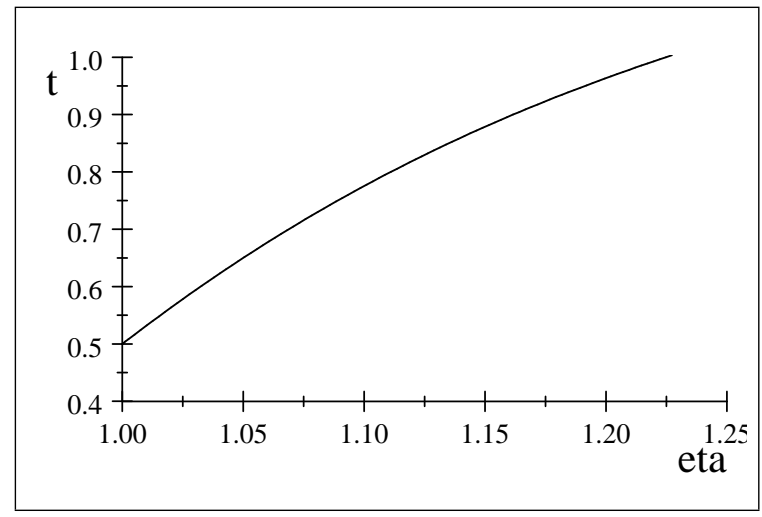

Discriminatory task assignment rule $t(t<1)$ as a function of relative job importance $\eta$.

This has clear implications. Discrimination should be less prevalent in jobs where tasks vary greatly in importance. By extension, this type of discrimination plays no role in assignment decisions where the less important task represents the employee losing his job. There, the motivation of the employee who looses out on the promotion is hardly relevant to the firm. This would cover up-or-out policies as well as situations in which the manager is forced to lay off one employee.

Finally, it is worth noting that our analysis suggests that by task design organizations can sometimes avoid discrimination.

\section{Common Prejudice}

In Section 4, we have demonstrated that discrimination is likely even if the ability of both employees come from the same distribution. The motivation of this assumption is that the existence of discrimination is less surprising in situations where employees 
differ ex ante. In the present section, we examine situations where prejudice, correct or not, suggest that top talents all come from an identifiable group. For instance, in situations where physical strength is important, there may well be a common prejudice that all top talents will be male. ${ }^{5}$

We modify the basic game as follows. Suppose that both employees believe that $a_{1} \sim U[0, \beta]$, with $\beta>1$, while $a_{2} \sim U[0,1]$. Thus only employee 1 can be a top talent with ability above 1 . Let both abilities be drawn independently. The optimal assignment rule is, as before, given by (4). We distinguish two cases. First, $t \geq \beta$. In this case, all equilibria are discriminatory against Employee 1 . Second, $t<\beta$. This second case allows for discriminatory equilibria in favor of Employee 1, i.e. $t<1$.

Consider the first case, $t \geq \beta$. By (4) we have that in equilibrium

$$
\begin{aligned}
t & =\frac{\left(\frac{\int_{0}^{\frac{\beta}{t}} \int_{0}^{t a_{2}} \frac{1}{\beta} a_{2} d a_{1} d a_{2}+\int_{\frac{\beta}{t}}^{1} \int_{0}^{\beta} \frac{1}{\beta} a_{2} d a_{1} d a_{2}}{\int_{0}^{\frac{\beta}{t}} \int_{0}^{t a_{2}} \frac{1}{\beta} d a_{1} d a_{2}+\int_{\frac{\beta}{t}}^{1} \int_{0}^{\beta} \frac{1}{\beta} d a_{1} d a_{2}}-\frac{\int_{0}^{\frac{\beta}{t}} \int_{t a_{2}}^{\beta} \frac{1}{\beta} a_{2} d a_{1} d a_{2}}{\int_{0}^{\frac{\beta}{t}} \int_{t a_{2}}^{\beta} \frac{1}{\beta} d a_{1} d a_{2}}\right)}{\left(\frac{\int_{0}^{\frac{\beta}{t}} \int_{t a_{2}}^{\beta} \frac{1}{\beta} a_{1} d a_{1} d a_{2}}{\int_{0}^{\frac{\beta}{t}} \int_{t a_{2}}^{\beta} \frac{1}{\beta} d a_{1} d a_{2}}-\frac{\int_{0}^{t} \frac{1}{\beta} a_{1} d a_{1} d a_{2}+\int_{\frac{\beta}{t}}^{1} \int_{0}^{\beta} \frac{1}{\beta} a_{1} d a_{1} d a_{2}}{\int_{0}^{\frac{\beta}{t}} \int_{0}^{t a_{2}} \frac{1}{\beta} d a_{1} d a_{2}+\int_{\frac{\beta}{t}}^{1} \int_{0}^{\beta} \frac{1}{\beta} d a_{1} d a_{2}}\right)} \\
= & \frac{3 t-2 \beta}{t \beta}
\end{aligned}
$$

This yields two solutions for $t$ :

$$
t^{*} \in\left\{\frac{3-\sqrt{9-8 \beta^{2}}}{2 \beta}, \frac{3+\sqrt{9-8 \beta^{2}}}{2 \beta}\right\}
$$

We learn three things from (6). First, if $\beta>\sqrt{\frac{9}{8}}$, no real value of $t$ solving (6) exists. Second, for $\beta \rightarrow 1$, the equilibria converge to $t=1$ and $t=2$. Third, the maximal discrimination against Employee 1 decreases in $\beta$.

\footnotetext{
${ }^{5}$ Goldin and Rouse (2000) state that also in music such prejudice is not uncommon: "Many of the most renowned conductors have, at one time or another, asserted that female musicians are not the equal of male musicians" (p. 719). They proceed to show that the chances of female musicians to be hired at (top) symphony orchestras were improved by the introduction of blind auditions. This result suggests both that there was a prejudice against women, and that these beliefs were either exaggerated or wrong.
} 
Now suppose that $t<\beta$. Then, (4) implies that

$$
\begin{aligned}
t & =\frac{\left(\frac{\int_{0}^{1} \int_{0}^{t a_{2}} \frac{1}{\beta} a_{2} d a_{1} d a_{2}}{\int_{0}^{1} \int_{0}^{t a_{2}} \frac{1}{\beta} d a_{1} d a_{2}}-\frac{\int_{0}^{1} \int_{t a_{2}}^{\beta} \frac{1}{\beta} a_{2} d a_{1} d a_{2}}{\int_{0}^{1} \int_{t a_{2}}^{\beta} \frac{1}{\beta} d a_{1} d a_{2}}\right)}{\left(\frac{\int_{0}^{1} \int_{t a_{2}}^{\beta} \frac{1}{\beta} a_{1} d a_{1} d a_{2}}{\int_{0}^{1} \int_{t a_{2}}^{\beta} \frac{1}{\beta} d a_{1} d a_{2}}-\frac{\int_{0}^{1} \int_{0}^{t a_{2}} \frac{1}{\beta} a_{1} d a_{1} d a_{2}}{\int_{0}^{1} \int_{0}^{t a_{2}} \frac{1}{\beta} d a_{1} d a_{2}}\right)} \\
= & \frac{1}{3 \beta-2 t}
\end{aligned}
$$

Solving this condition for $t$ yields $^{6}$

$$
t^{*}=\frac{3}{4} \beta-\frac{1}{4} \sqrt{9 \beta^{2}-8}
$$

Two features of (7) are worth mentioning. First, for $\beta \rightarrow 1$, this equilibrium converges to $t=\frac{1}{2}$. Second, the larger is $\beta$, the stronger is the discrimination against Employee 2. ${ }^{7}$ It follows that in this equilibrium the manager discriminates against Employee 2. The following proposition summarizes the findings.

Proposition 5 Consider the modified basic game with $a_{1} \sim U[0, \beta], \beta>1$.

- Suppose $\beta \in\left(1, \sqrt{\frac{9}{8}}\right]$. Then in equilibrium $t^{*} \in\left\{\frac{3 \beta-\sqrt{9 \beta^{2}-8}}{4}, \frac{3-\sqrt{9-8 \beta^{2}}}{2 \beta}, \frac{3+\sqrt{9-8 \beta^{2}}}{2 \beta}\right\}$. Each equilibrium is discriminatory.

- In the first equilibrium, $t^{*}=\frac{3 \beta-\sqrt{9 \beta^{2}-8}}{4}$, the manager discriminates against Employee 2. The higher is $\beta$, the stronger the manager discriminates.

- In the other two equilibria the manager discriminates against Employee 1. The higher is $\beta$, the lower is the maximal degree of discrimination against Employee 1.

- Suppose $\beta>\sqrt{\frac{9}{8}}$. Then in equilibrium $t^{*}=\frac{3 \beta-\sqrt{9 \beta^{2}-8}}{4}$. In this equilibrium the manager discriminates against Employee 2. The higher is $\beta$, the stronger the manager discriminates.

\footnotetext{
${ }^{6}$ Note that $t=\frac{3}{4} \beta+\frac{1}{4} \sqrt{9 \beta^{2}-8}$ is not an eligible solution as $t<\beta$ by assumption.

${ }^{7}$ Note that $\frac{\partial}{\partial \beta} \frac{1}{4}\left(3 \beta-\sqrt{9 \beta^{2}-8}\right)=\frac{1}{4}\left(3-\frac{1}{2 \sqrt{9 \beta^{2}-8}} 18 \beta\right)$. This is negative as $6 \sqrt{9 \beta^{2}-8}<$ $18 \beta \Longleftrightarrow \sqrt{9 \beta^{2}-8}<\sqrt{9 \beta^{2}}=3 \beta$.
} 
Proposition 5 shows that an increase in $\beta$ either weakens discrimination against Employee 1 or strenghtens discrimination against Employee 2. For high values of $\beta$, the unique equilibrium is one where the manager severely discriminates against Employee 2. The intuition behind these results is straightforward. First, for any $t<\beta$, Employee 1 looses more self-confidence if he learns that $a_{1}<t$ when $\beta$ is higher. In contrast, for higher $\beta$ the self-confidence of Employee 2 is less affected by the assignment decision. The reason is that it is more likely that Employee 2 will get the minor task regardless of her ability, so because $a_{1}>t$, rather than due to her ability, because $a_{2}<\frac{a_{1}}{t}$. Consequently, the manager has stronger incentives to discriminate in favor of Employee 1. Second, the manager's scope for confidence management depends on the extent to which an employee is uncertain about his ability. To see this, suppose that Employee 2 receives a private signal regarding his ability which is almost always conclusive. Then, the assignment decision of the manager would hardly affect Employee 2's perception of his ability, and in turn his effort. Granting employee 2 the major task cannot motivate much. Here, by $\beta>1$, Employee 2 has a better idea about his ability than Employee 1. Consequently, the manager is less willing to favor Employee 2, if at all. Concluding, commonly shared prejudices in favor of one employee mitigate or prevent discrimination against him, while they aggrevate discrimination against the other employee.

\section{Discrimination and initial beliefs}

In our model managers discriminate in order to avoid demotivating employees. An employee who expects to be favored learns that he cannot be good when he does not receive the preferred task. How much this knowledge affects his motivation depends on his prior beliefs. In this section we relax the assumption that ability is drawn from a uniform distribution. Rather we assume that ability is drawn from a distribution with a linear density function with support $[0,1]$. Our aim is to see whether discrimination is aggrevated or mitigated if employees have more positive, or more negative priors on their own ability.

Suppose that the density function of the ability levels is given by $f\left(a_{i}\right)=\gamma+$ $2(1-\gamma) a_{i}$ where $a_{i} \in[0,1]$ and $\gamma \in[0,2]^{8}$ Note that for $\gamma=1$, we have the same

\footnotetext{
${ }^{8}$ This condition ensures full support over the interval $[0,1]$.
} 
ability distributions as in the basic model. For $\gamma<1$ employees are more likely to have high ability, while for $\gamma>1$ employees are more likely to have low ability. We obtain the following result (the proof is in Appendix C).

Proposition 6 Consider the generalized basic game, where the density function of $a_{i}$ is given by $f\left(a_{i}\right)=\gamma+2(1-\gamma) a_{i}$ where $a_{i} \in[0,1]$ and $\gamma \in[0,2]$ and $f\left(a_{i}\right)=0$ for all $a_{i} \notin[0,1]$. Then, in any discriminatory equilibrium, discrimination is more severe if $\gamma<1$ while it is less severe, or non-existent if $\gamma>1$.

The intuition for this result is simple. Suppose Employee 1 is the expected favorite, so $t<1$. If the preferred task is assigned to Employee 2, Employee 1 learns that his ability must be below $t$. If a priori he believed it unlikely that his ability was higher than $t$, then this is not very informative. Consequently, he is less demotivated by not getting the preferred task, making it less costly for the manager to promote Employee 2. In contrast, if a priori the employee believed it unlikely that his ability was below $t$, then not receiving the preferred task will have a large impact on his self-confidence and effort. We conclude that managers' incentives to discriminate are stronger in environments where employees are more likely to be able.

\section{Conclusions}

This article offers a new theory of discrimination in the workplace. We have shown that in a task-assignment or promotion setting, managers tend to discriminate in favor of the favorite out of fear that passing the favorite would severely damage his confidence in his ability.

We are silent about what in practice exactly triggers discrimination. It can be gender, religion, skin color, age, or a love for red wine. This makes it sometimes hard to discover discrimination. An outsider may observe a glass ceiling for women. It is harder for an outsider to observe a glass ceiling for white wine lovers. The instability of the non-discriminatory equilibrium makes it hard to combat discrimination. For example, once discrimination against women is resolved, it is likely to be replaced by another form of discrimination.

Our results have some implications which may be used to distinguish it from the main other types of discrimination. For example, in self-fullfilling prophecy 
models, a manager never promotes a candidate that is ex post weaker. In our model, the manager sometimes does. In a model where managers would have a taste for discrimination, discrimination would be particularly severe in an up or out setting. In our model, discrimination does not occur in an up or out setting.

Our model is a static one. We are aware that discrimination on the workfloor also has dynamic implications. Females have incentives to eschew organizations where they are discriminated. As a consequence, when discrimination is easy to observe, it may eventually lead to segregation. Employees may also quit when they learn that their kinds are not the favorite. This threat of quitting may weaken managers' incentives to discriminate. We leave these dynamic considerations for future research.

\section{References}

Akerlof, G.A. (1985), "Discriminatory, status-based wages among tradition-oriented, stochastically trading coconut producers," Journal of Political Economy 93(2), 265276.

Arrow, K.J. (1973), "The theory of discrimination," in Discrimination in Labor Markets (eds: Ashenfelter O. and A. Rees), Princeton University Press, 3-33.

Becker, G. (1957), The Economics of Discrimination, University of Chicago Press, Chicago.

Bénabou, R. and J. Tirole (2003), "Intrinsic and extrinsic motivation," Review of Economic Studies 70, 489-520.

Coate, S. and G. Loury (1993), "Will affirmative action policies eliminate negative stereotypes?," American Economic Review 83(5), 1220-1242.

Crutzen, B.S.Y., O.H. Swank and B. Visser (2013), "Confidence management: on interpersonal comparisons in teams," Journal of Economics and Management Strategy 22(4), 744-767.

Goldin, C. and C. Rouse (2000), "Orchestrating impartiality: The impact of "blind" auditions on female musicians", American Economic Review 90(4), 715-741.

Ishida, J. (2006), "Optimal promotion policies with the looking-glass effect," Journal of Labor Economics 24(4), 857-877.

Lazear E.P. and S. Rosen (1981), "Rank-order tournaments as optimum labor contracts," Journal of Political Economy 89(5), 841-864. 
Lazear E.P. and S. Rosen (1990), "Chicago male-female wage differentials in job ladders," Journal of Labor Economics 8(1), S106-S123.

Mailath, G., L. Samuelson, and A. Shaked (2000), "Endogenuous inequality in integrated labor markets with two-sided search," American Economic Review 95(4), $1327-1340$.

Milgrom P. and S. Oster (1987), "Job discrimination, market forces, and the invisibility hypothesis," Quarterly Journal of Economics 102(3), 453-476.

Pęski, M. and B. Szentes (2013), "Spontaneous discrimination," American Economic Review 103(6), 2412-2436.

Phelps, E.S. (1972), "The statistical theory of racism and sexism", American Economic Review 62(4), 659-661.

Prendergast, C. (1992), "Career development and specific human capital collection," Journal of the Japanese and International Economies 6, 207-227.

Takeuchi, H. (1985), "Motivation and productivity," in The Management Challenge (ed: L. Thurow), MIT Press, Cambridge, MA.

\section{A Proof of Proposition 3}

We prove each bullet of the proposition in turn. W.l.o.g. we restrict $t$ to $t \in[0,1]$. First, the manager anticipates the effort levels resulting from her assignment rule. Her expected payoff when choosing $t$ equals

$$
\begin{aligned}
& \int_{0}^{1} \int_{t a_{2}}^{1}\left(a_{1} \frac{1}{3 t-6}\left(t^{2}-3\right)+a_{2} \frac{2 t-3}{3 t-6}\right) d a_{1} d a_{2}+ \\
& \int_{0}^{1} \int_{0}^{t a_{2}}\left(a_{1} \frac{1}{3} t+a_{2} \frac{2}{3}\right) d a_{1} d a_{2} \\
= & \frac{\left(9-2 t-3 t^{2}+t^{3}\right)}{9(2-t)}
\end{aligned}
$$

For $t \in[0,1], t=1$ maximizes (8).

Second, we show that an employee prefers to be favored. W.l.o.g. consider Employee 1. Employee 1 anticipates the effort levels resulting from the assignment 
rule. His expected payoff when choosing $t$ equals

$$
\begin{aligned}
& \int_{0}^{1} \int_{t a_{2}}^{1}\left(a_{1} \frac{1}{3 t-6}\left(t^{2}-3\right)-\frac{1}{2}\left(\frac{1}{3 t-6}\left(t^{2}-3\right)\right)^{2}\right) d a_{1} d a_{2}+ \\
& \int_{0}^{1} \int_{0}^{t a_{2}}\left(a_{1} \frac{1}{3} t-\frac{1}{2}\left(\frac{1}{3} t\right)^{2}\right) d a_{1} d a_{2} \\
= & \frac{\left(2 t^{3}-6 t^{2}+9\right)}{36(2-t)}
\end{aligned}
$$

Taking first order derivatives we get

$$
\frac{\partial}{\partial t} \frac{\left(2 t^{3}-6 t^{2}+9\right)}{36(2-t)}=\frac{\left(9-24 t+18 t^{2}-4 t^{3}\right)}{36(t-2)^{2}}
$$

which is negative at $t=1$ and positive at $t=0$. Thus the optimal level of $t$ for Employee 1 is strictly lower than 1 and strictly larger than 0 (in fact, his optimal assignment rule would be $t=\frac{3}{2}-\frac{1}{2} \sqrt{3}$, which is roughly equal to 0.634 ).

Third, we show that total expected payoff of the employees is maximized at $t=1$. This means that employees would prefer no discrimination ex ante, i.e. before they know who would be the expected favorite. As we already know the expected payoff of the favorite, we now calculate the expected payoff of the employee who is disfavored. This is equal to:

$$
\begin{aligned}
& \int_{0}^{1} \int_{t a_{2}}^{1}\left(a_{2} \frac{2 t-3}{3 t-6}-\frac{1}{2}\left(\frac{2 t-3}{3 t-6}\right)^{2}\right) d a_{1} d a_{2} \\
+ & \int_{0}^{1} \int_{0}^{t a_{2}}\left(a_{2} \frac{2}{3}-\frac{1}{2}\left(\frac{2}{3}\right)^{2}\right) d a_{1} d a_{2} \\
= & \frac{(9-4 t)}{36(2-t)}
\end{aligned}
$$

Summing the total expected payoffs of the two employees, and differentiating with respect to $t$ on $[0,1]$ we obtain that $t=1$ is optimal.

$$
\begin{aligned}
\frac{\left(2 t^{3}-6 t^{2}+9\right)}{36(2-t)}+\frac{(9-4 t)}{36(2-t)} & =\frac{\left(9-2 t-3 t^{2}+t^{3}\right)}{18(2-t)} \\
\frac{\partial}{\partial t} \frac{\left(9-2 t-3 t^{2}+t^{3}\right)}{18(2-t)} & =\frac{1}{18} \frac{(t-1)^{2}}{(t-2)^{2}}(5-2 t)
\end{aligned}
$$


As $\frac{1}{18} \frac{(t-1)^{2}}{(t-2)^{2}}(5-2 t)>0$ on $t \in[0,1]$ we obtain that it is in the joint interest of the employees to have no discrimination. This concludes the proof. $\square$

\section{B Proof of Proposition 4}

We first prove the equilibria. After that we discuss the stability results. The manager is indifferent between sending $m=1$ and sending $m=2$ if

$$
a_{1}=t a_{2}, \text { with } t=\frac{\eta^{2} E\left(a_{2} \mid 2\right)-E\left(a_{2} \mid 1\right)}{\eta^{2} E\left(a_{1} \mid 1\right)-E\left(a_{1} \mid 2\right)}
$$

Analogous to the derivation of (5) we find

$$
t=\frac{\frac{2}{3} \eta^{2}-\frac{3-2 t}{6-3 t}}{\frac{3-t^{2}}{6-3 t} \eta^{2}-\frac{1}{3} t}
$$

Solving for $t$, we obtain $t \in\left\{1, t^{*}\right\}$, where $t^{*}=\left(\frac{\left(\sqrt{13-26 \eta^{2}+17 \eta^{4}}-1-\eta^{2}\right)}{2\left(\eta^{2}-1\right)}\right)$. Note that $(i)$ that $t$ increases in $\eta$, so any discrimination becomes less severe as $\eta$ increases; (ii) for $\eta=1$ we have $t^{*}=\frac{1}{2}$; and (iii) for $\eta \geq \sqrt{\frac{3}{2}}, t^{*} \geq 1$. The latter implies that for $\eta \geq \sqrt{1.5}, t=1$ is the unique equilibrium. ${ }^{9}$

Regarding stability, we establish for any arbitrary belief about assignment rule $t$, where w.l.o.g. $t \in[0,1]$, whether $\frac{\frac{2}{3} \eta^{2}-\frac{3-2 t}{6-3 t}}{\frac{3-t^{2}}{6-3 t} \eta^{2}-\frac{1}{3} t}$ is higher or lower than $t$. Due to the $\eta$ term, our proof follows a different route than the proof of Proposition 2. We first note that in equilibrium we have $\frac{\frac{2}{3} \eta^{2}-\frac{3-2 t}{6-3 t}}{\frac{3-t^{2}}{6-3 t} \eta^{2}-\frac{1}{3} t}=t$. Then we check whether at any particular equilibrium $\frac{\partial}{\partial t} \frac{\frac{2}{3} \eta^{2}-\frac{3-2 t}{6-3 t}}{\frac{3-t^{2}}{6-3 t} \eta^{2}-\frac{1}{3} t}$ is larger or smaller than $1\left(=\frac{\partial}{\partial t} t\right)$. If $\frac{\partial}{\partial t} \frac{\frac{2}{3} \eta^{2}-\frac{3-2 t}{6-3 t}}{\frac{3-t^{2}}{6-3 t} \eta^{2}-\frac{1}{3} t}<1$, then the equilibrium is stable. If $\frac{\partial}{\partial t} \frac{\frac{2}{3} \eta^{2}-\frac{3-2 t}{6-t^{2}}}{\frac{3-t^{2}}{6-3 t} \eta^{2}-\frac{1}{3} t}>1$ it is unstable. As $\frac{\frac{2}{3} \eta^{2}-\frac{3-2 t}{6-3 t}}{\frac{3-t^{2}}{6-3 t} \eta^{2}-\frac{1}{3} t}$ is continuous in $t$, if $\frac{\frac{2}{3} \eta^{2}-\frac{3-2 t}{6-3 t}}{\frac{3-t^{2}}{6-3 t} \eta^{2}-\frac{1}{3} t}<t$ for some $t \in\left(t^{*}, 1\right)$, then $\frac{\frac{2}{3} \eta^{2}-\frac{3-2 t}{6-3 t}}{\frac{3-t^{2}}{6-3 t} \eta^{2}-\frac{1}{3} t}<t$ for all $t \in\left(t^{*}, 1\right)$.

$$
\frac{\partial}{\partial t} \frac{\left(\eta^{2} E(2 \mid 2, t)-E(2 \mid 1, t)\right)}{\left(\eta^{2} E(1 \mid 1, t)-E(1 \mid 2, t)\right)}=-\frac{2\left(t^{2} \eta^{4}-2 t^{2} \eta^{2}+t^{2}-4 t \eta^{4}+7 t \eta^{2}-3 t+3 \eta^{4}-7 \eta^{2}+3\right)}{\left(3 \eta^{2}-2 t-t^{2} \eta^{2}+t^{2}\right)^{2}}
$$

For $t=1$, we obtain

\footnotetext{
${ }^{9}$ The reason is that $\frac{1}{2(\eta-1)}\left(\sqrt{13-26 \eta+17 \eta^{2}}-1-\eta\right)>1$ for $\eta>\frac{3}{2}$. Consequently, there is no promotion rule $t, t<1$, which is a best reply when it is anticipated.
} 


$$
\begin{aligned}
\frac{\partial}{\partial t} \frac{\left(\eta^{2} E(2 \mid 2, t)-E(2 \mid 1, t)\right)}{\left(\eta^{2} E(1 \mid 1, t)-E(1 \mid 2, t)\right)} & =\frac{\left(4 \eta^{2}-2\right)}{\left(2 \eta^{2}-1\right)^{2}} \\
& =\frac{2}{2 \eta^{2}-1}
\end{aligned}
$$

The $t=1$ equilibrium is unstable if a discriminatory equilibrium exists. To see this, note that we have $\frac{2}{2 \eta^{2}-1}<1$ for $\eta>\sqrt{\frac{3}{2}}$, while $\frac{2}{2 \eta^{2}-1}>1$ for $\eta<\sqrt{\frac{3}{2}}$. Now we consider the $t=t^{*}$ equilibrium. As $t^{*}$ is an unwieldy expression, we avoid it as follows. First we rewrite (11):

$$
\begin{aligned}
\eta(t) & =\sqrt{\frac{E(2 \mid 1)-t E(1 \mid 2)}{E(2 \mid 2)-t E(1 \mid 1)}} \\
& =\sqrt{\frac{\frac{3-2 t}{6-3 t}-t^{2} \frac{1}{3}}{\frac{2}{3}-t \frac{3-t^{2}}{6-3 t}}}
\end{aligned}
$$

After some rearranging, we obtain

$$
\eta(t)=\sqrt{\frac{3+t-t^{2}}{4-t-t^{2}}}
$$

Substituting (13) in (12) and evaluating at $t=t^{*}$ we obtain

$$
\frac{\partial}{\partial t} \frac{\left(\eta^{2} E\left(2 \mid 2, t=t^{*}\right)-E\left(2 \mid 1, t=t^{*}\right)\right)}{\left(\eta^{2} E\left(1 \mid 1, t=t^{*}\right)-E\left(1 \mid 2, t=t^{*}\right)\right)}=\frac{\left(2+4 t^{*}-4\left(t^{*}\right)^{2}+2\left(t^{*}\right)^{3}\right)}{9-5 t^{*}}
$$

We now establish that $\frac{\left(2+4 t^{*}-4\left(t^{*}\right)^{2}+2\left(t^{*}\right)^{3}\right)}{9-5 t^{*}}<1$.

$$
\begin{aligned}
\left(2+4 t^{*}-4\left(t^{*}\right)^{2}+2\left(t^{*}\right)^{3}\right) & <9-5 t^{*} \\
2\left(t^{*}\right)^{3}-4\left(t^{*}\right)^{2}+9 t^{*}-7 & <0 \\
-\left(1-t^{*}\right)\left(7-2 t^{*}+2\left(t^{*}\right)^{2}\right) & <0
\end{aligned}
$$

It is clear that the last inequality holds for any $t^{*} \in(0,1)$. Thus the equilibrium $t=t^{*}$ is stable. 


\section{Proof of Proposition 6}

The optimal assignment rule is, as before, given by (4). We first consider the case where $t \leq 1$. The beliefs are as follows: $E\left(a_{1} \mid 1\right)=\frac{\int_{0}^{1} \int_{t a_{2}}^{1}\left(\gamma+2(1-\gamma) a_{1}\right)\left(\gamma+2(1-\gamma) a_{2}\right) a_{1} d a_{1} d a_{2}}{\int_{0}^{1} \int_{t a_{2}}^{1}\left(\gamma+2(1-\gamma) a_{1}\right)\left(\gamma+2(1-\gamma) a_{2}\right) d a_{1} d a_{2}}$, $E\left(a_{2} \mid 1\right)=\frac{\int_{0}^{1} \int_{t a_{2}}^{1}\left(\gamma+2(1-\gamma) a_{1}\right)\left(\gamma+2(1-\gamma) a_{2}\right) a_{2} d a_{1} d a_{2}}{\int_{0}^{1} \int_{t a_{2}}^{1}\left(\gamma+2(1-\gamma) a_{1}\right)\left(\gamma+2(1-\gamma) a_{2}\right) d a_{1} d a_{2}}, E\left(a_{2} \mid 2\right)=\frac{\int_{0}^{1} \int_{0}^{t a_{2}}\left(\gamma+2(1-\gamma) a_{1}\right)\left(\gamma+2(1-\gamma) a_{2}\right) a_{2} d a_{1} d a_{2}}{\int_{0}^{1} \int_{0}^{t a_{2}}\left(\gamma+2(1-\gamma) a_{1}\right)\left(\gamma+2(1-\gamma) a_{2}\right) d a_{1} d a_{2}}$, and $E\left(a_{1} \mid 2\right)=\frac{\int_{0}^{1} \int_{0}^{t a_{2}}\left(\gamma+2(1-\gamma) a_{1}\right)\left(\gamma+2(1-\gamma) a_{2}\right) a_{1} d a_{1} d a_{2}}{\int_{0}^{1} \int_{0}^{t a_{2}}\left(\gamma+2(1-\gamma) a_{1}\right)\left(\gamma+2(1-\gamma) a_{2}\right) d a_{1} d a_{2}}$. Solving for $t=\frac{E\left(a_{2} \mid 2\right)-E\left(a_{2} \mid 1\right)}{E\left(a_{1} \mid 1\right)-E\left(a_{1} \mid 2\right)}$ we obtain two solutions consistent with $t \leq 1$. The first is the non-discriminatory equilibrium $t=1$. The second solution is

$$
t^{*}=\frac{\left(12-74 \gamma+37 \gamma^{2}-5 \gamma^{3}+\sqrt{144 \gamma+5644 \gamma^{2}-8476 \gamma^{3}+4149 \gamma^{4}-730 \gamma^{5}+25 \gamma^{6}+144}\right)}{12(\gamma-1)(3 \gamma-8)}
$$

We now show that $t^{*}<\frac{1}{2} \Leftrightarrow \gamma<1$ and $t^{*}>\frac{1}{2} \Leftrightarrow \gamma>1$. The key is that $12(\gamma-1)(3 \gamma-8)$ is positive if $\gamma \in(0,1)$ while it is negative if $\gamma \in(1,2)$. Therefore for $\gamma<1$ we obtain

$$
\begin{aligned}
\frac{\left(12-74 \gamma+37 \gamma^{2}-5 \gamma^{3}+\sqrt{144 \gamma+5644 \gamma^{2}-8476 \gamma^{3}+4149 \gamma^{4}-730 \gamma^{5}+25 \gamma^{6}+144}\right)}{12(\gamma-1)(3 \gamma-8)} & <\frac{1}{2} \\
\sqrt{144 \gamma+5644 \gamma^{2}-8476 \gamma^{3}+4149 \gamma^{4}-730 \gamma^{5}+25 \gamma^{6}+144} & <5 \gamma^{3}-19 \gamma^{2}+8 \gamma+36 \\
\left(144 \gamma+5644 \gamma^{2}-8476 \gamma^{3}+4149 \gamma^{4}-730 \gamma^{5}+25 \gamma^{6}+144\right) & <\left(5 \gamma^{3}-19 \gamma^{2}+8 \gamma+36\right)^{2} \\
36(8-3 \gamma)\left(-11 \gamma+5 \gamma^{2}-4\right)(\gamma-1)^{2} & <0
\end{aligned}
$$

which condition holds, as $\left(-11 \gamma+5 \gamma^{2}-4\right)<0$ for all $\gamma \in[0,1)$.

For $\gamma \in(1,2)$, similar calculations give the condition that $t^{*}>\frac{1}{2}$ if $\left(-11 \gamma+5 \gamma^{2}-4\right)<$ 0 . Therefore $\gamma>1$ decreases discrimination. We now show that the discriminatory equilibrium can cease to exist if $\gamma>1$. Suppose $\gamma=1$. Then (14) gives $t^{*}=1.0567$. This is not an eligible solution as, by assumption, $t \leq 1$.

We conclude the proof by pointing out that the case for $t \geq 1$ is symmetric to $t \leq 1$ 